\title{
Entrevista com Maria Lourdes Motter
}

\section{As telenovelas e práticas culturais}

\begin{abstract}
Apresentação
$\mathrm{O}$ gênero telenovela tem marcado as práticas de recepção mediática em diversos contextos culturais que na contemporaneidade se servem dos produtos da indústria cultural.

No Brasil, o gênero tem se consagrado há várias décadas. $\mathrm{O}$ seu estudo no entanto ainda é incipiente oferecendo pistas diversas sobre a necessidade do seu aprofundamento.

Maria Lourdes Motter tem pesquisado o tema junto a Escola de Comunicações e Artes da Universidade de São Paulo e tem diversas publicações a respeito, entre elas, Ficção e Realidade: a construção do cotidiano na telenovela, São Paulo, Alexia Cultural, 2003; e Fiç̧ão e história: imprensa e construção da realidade, São Paulo, Villipress, 2001.

Em entrevista adiante apresentada, a pesquisadora aborda tópicos que ajudam a compreender a complexidade do gênero e de suas práticas especialmente no contexto cultural brasileiro.
\end{abstract}

NO: Pode-se dizer que o gênero folhetim foi mais importante na construção do êxito da telenovela brasileira entre os brasileiros do que a própria televisão como veiculo?

MLM: O gênero é fundamental e a própria televisão como veiculo depende do gênero. No decorrer da história da televisão brasileira, o folhetim foi estruturando a telenovela ao mesmo tempo que ela foi a grande sustentação para a consolidação da própria televisão. Na concorrência comercial, emissoras encontram dificuldade quando sua programação não se apóia em uma base estável, não tem um gênero forte no qual se sustentar e, periodicamente, prioriza um gênero diferente, que ora é o esporte, ora a notícia, ora os enlatados (filmes, desenhos), etc. No Brasil, a emissora que tem a sustentação na telenovela e no folhetim é a que tem estabilidade maior. Estabilidade de audiência, de programação, estabilidade econômica. Os três fatores têm uma relação direta. Se antes nós podíamos apreciar o folhetim pela via do jornal, pela via do rádio, depois, pela via da televisão, a telenovela ganha uma expressão muito grande na televisão e, naturalmente, isso vai concorrer para a afirmação do próprio veículo, a ponto de a televisão ter acabado se tornando o principal produto brasileiro. Em termos de Brasil, o que se percebe é que este modelo é um modelo de sucesso. Claro que isso não quer dizer que o modelo a que se chegou aqui com a telenovela brasileira, vai funcionar bem fora do pais, embora ela também tenha uma grande aceitação fora. Aqui temos essa produção se fazendo concomitante à exibição, que garante a possibilidade de estabelecer mudanças de curso, de permitir a introdução e a interferência do cotidiano, dos acontecimentos que vão ocorrendo, graças à longa duração, que também é, em geral, uma característica do produto brasileiro, porque nos outros países, em geral, a duração é bem menor. O nosso próprio produto é reeditado para exportação com o objetivo de reduzi-lo, tomá-lo compacto. A
Maria Lourdes Motter é professora Livre-Docente do Departamento de Comunicações e Artes da ECA-USP, coordenadora do núcleo "Cotidiano e Linguagem" do curso de pós-graduação Gestão de Processos Comunicacionais da ECA-USP, coordenadora e pesquisadora do NPTN (Núcleo de Pesquisas de Telenovela). 
grande vantagem da telenovela e a grande motivação que a sustenta é exatamente sua plasticidade para incorporar novidades, acertos, no curso mesmo da sua exibição, o que faz o produto ser sempre novo, sempre aberto à possibilidade de acertar um curso que não está indo bem. Hoje o folhetim é algo que está não só presente como incorporado à vida brasileira. Os acréscimos, o jeito brasileiro de fazer, seja no sentido do cuidado artístico, seja da própria infra-estrutura criada bem como na tecnologia que participa da produção, vão significar na vida cotidiana e vão realmente estar de modo factual atuando junto à audiência.

NO: No caso estrangeiro, onde a telenovela também chegou, pode-se dizer que a televisão passou a ter um papel diferenciado dentro da sociedade, na medida em que o gênero folhetim foi incorporado na programação?

MLM: Nós temos uma tradição de valorização e de apreciação dessa ficção diferentemente de outros países. Nos outros países a televisão vai estar basicamente preocupada com o factual, com programas de entrevistas, de auditório, de cunho educativo e/ou cultural, reservando-se a ficção para filmes, por exemplo, e com uma série de outros aspectos, quando nós sabemos que aqui a qualidade e o maior investimento vão estar justamente na ficção produzida pela própria televisão. No Brasil ela passa a ter esse espaço prioritário, a incorporar o factual, o noticiário, enfim, ela se expandiu de tal modo e adquiriu uma importância tal que ela inclui tudo, o reality show, o show. Enfim, ela vai num processo de mudança gradual e de atualização, incorporando todos os outros gêneros, e acaba sendo realmente um super-gênero.

NO: O fato da televisão ser um veículo urbano e popular, e ter a telenovela como seu elemento mais significativo, permite dizer que a telenovela brasileira é parte constituinte da cultura popular?
MLM: Eu acho que aí a relação é muito complexa. Eu não diria que ela é apenas uma cultura de massa, ou somente popular. Ela é um elemento da cultura que independentemente de uma classificação no todo, tem uma capacidade de penetrar, recolher e transformar. Nesse processo de reaproveitamento e de transformação ela vai devolver alguma coisa que não é cultura de massa ou popular, mas algo diferente. Eu prefiro dizer que ela é parte constituinte da cultura brasileira.

NO: A questão do horário em que a principal telenovela da rede de maior audiência, a Rede Globo, é exibida, bem como $o$ fato dela suceder $o$ telejornalismo, não se configura como um fator domesticador do telespectador, logo, do êxito de audiência da telenovela?

MLM: Olha, eu acho que não. Eu acho que ser colocada nesse horário é uma questão que entra realmente com o momento do entretenimento, do descanso. Ela está inserida ali com uma função muito clara. Pelo telejornal eu recebo as notícias, as catástrofes do mundo, todas as coisas que aconteceram, em geral as boas noticias são sempre muito poucas, e a ficção é exatamente o momento de relaxamento, quer dizer, o que vem depois do noticiário. Do ponto de vista do que seria espaço de trabalho, nós teríamos ainda o telejornal no espaço do trabalho que vai orientar meu dia seguinte, que vai orientar a previsão do tempo, a economia, enfim, são coisas do gênero muito ligadas a minha vida cotidiana, enquanto que a ficção vai me afastar um pouco disso, trazer um relaxamento, um descanso. Se domesticar está sendo usado neste sentido, eu concordo. Mas eu não entenderia como algo domesticador no sentido de alienante. A própria telenovela, no seu modelo brasileiro atual, propõe questões muito importantes. Ela participa de uma maneira lúdica em um momento de descanso do telespectador, ele não está tendo que tomar decisões, pelo contrário, ele simplesmente está observando as 
coisas acontecerem diante dos seus olhos, mas ele não tem que viver o conflito e nem tem que passar pelo processo de tomar decisões no momento. Seriam duas maneiras de se pensar questões mesmo para reflexão, quer dizer, uma é você ser bombardeado diretamente pelos acontecimentos do mundo, e você ser envolvido, ter que levar a sério, como um problema imediato e pessoal, considerar aquilo para um planejamento do dia seguinte, enquanto que no caso da ficção você vai vivenciar uma série de problemas, uma série de questões que você pode não estar tendo como problema agora, mas que de repente vem depois ou serve pra você repensar uma serie de conceitos, de idéias que você tem a respeito de problemas individuais ou sociais. Pensaria na questão do homossexualismo, de determinadas doenças, do alcoolismo, enfim, há uma série de problemas que não são suficientemente discutidos, conhecidos e com os quais as pessoas não sabem lidar e nem têm orientação adequada para tratá-los de uma maneira pragmática, de uma maneira didática. $\mathrm{Na}$ medida em que as questões aparecem sendo construídas no dia-a-dia de maneira paulatina e são vivenciadas com intensidade dramática pelo telespectador, elas ganham clareza, importância, o que representa um ganho num país com a extensão territorial, diversidade geográfica, cultural e os desníveis sociais que tem o Brasil. Assim, acredito que as campanhas que passam pela telenovela têm a eficácia que campanhas institucionais não alcançam por seus meios tradicionais. Mas isso não quer dizer que a telenovela também faça revolução, ela dá uma contribuição enorme de uma maneira tranqüila, suave, para melhorar a compreensão das pessoas em relação a uma série de assuntos, por exemplo, questões que a ciência está começando a descobrir e discutir, que envolvem outros setores, outras campos importantes, campos jurídicos, da ética, enfim, as pessoas nem sabem ainda o que é isso, não chegam a uma definição, as leituras são escassas e não são didáticas. De repente, vendo a situação dramatizada, no contexto de uma história, passa a ser algo compreensível, tranqüilo, sem maiores problemas. Tudo que acontece ali tem uma grande repercussão, tudo que entra na ficção do horário nobre tem uma capacidade de abrangência tão grande que realmente não pode ter nada que não seja feito com muito cuidado, com muita seriedade, porque eles podem contribuir para educar, para informar, para desenvolver campanhas, mas podem também estimular comportamentos absolutamente inadequados. Pressupõe-se uma confiança na seriedade dos produtores e no rigor das pesquisas que exige da sociedade a vigilância permanente para que a confiança se reafirme. Esse protocolo é fundamental para a cordialidade das relações telenovela e audiência. Não se pode tolerar deslizes que venham a ser erros da sociedade como um todo.

NO: Nesse sentido, até que ponto a temática da narrativa importa na aceitação do público?

MLM: Eu acho que seria um ponto de partida. Estar diante de uma narrativa é algo excepcional. Na televisão não é diferente, agora aí entra o como, o contar com recursos outros que não apenas o da palavra. Na medida que você tem outras linguagens concorrendo para o contar essa história, obviamente esses outros elementos vão constituir uma questão fundamental. O modo de contar passa a ser importante. Eu colocaria em primeiro plano a própria questão da narrativa e depois viriam esses outros elementos, razões para se perceber por que uma é melhor que a outra, por que uma é aceita, uma tem uma vida longa e a outra desaparece. Entrariam essas variáveis do como, porque na verdade não temos histórias novas e inéditas para serem contadas. No tocante à telenovela brasileira, não há dúvida de que as temáticas relativas à realidade do país e da vida cotidiana brasileira têm um efeito catalisador potencialmente maior. 
NO: A relação identidade telespectador/personagem, sobretudo pensando no passado, na memória cultural do público, é o grande fator de sedução do gênero?

MLM: Sim, porque a gente sempre conta e ouve, aquilo que já aconteceu. Então a partir de você contar o que já aconteceu, nós já estamos diante de um passado, independente dele ser próximo ou mais distante. Então a gente só pode contar aquilo que já aconteceu e quando se volta mais no tempo, nós temos o problema de termos também informações díspares, soltas, lacunas. O que a ficção vai fazer, no caso da telenovela brasileira? No caso ela vai tentar produzir uma coerência, uma costura, dar um sentido para tudo isso, e daí realmente ela acaba nos trazendo elementos muitos importantes porque temos dificuldades de satisfazer a nossa necessidade de passado com os dados de memória que dispomos. Se pensarmos por exemplo na História como registro dos acontecimentos, o que depende de uma escrita, temos um discurso frio, descarnado de sentimentos, de elementos motivadores para identificação com o ser que é o agente do processo e que não aparece na dimensão de pessoa humana, com conflitos, paixões, dramas. Do ponto de vista do grande público, o interesse pelo conhecimento histórico passa a ser despertado quando essa dimensão excluída pela narrativa histórica ganha relevo na narrativa ficcional da telenovela ou de uma minissérie. Acho que a própria História que a gente acaba recebendo dessa maneira insípida acaba ganhando uma importância maior, um sentido maior, e uma maior facilidade de retenção da própria memória, porque ela vai estar ligada inclusive a fatores emocionais e vai ajudar na fixação. Eu entendo que essa recuperação da memória é importantíssima, mas a gente sabe perfeitamente que é uma reconstrução, que é algo que a gente tem que ler como uma ficção, de repente essa vai ser mais uma das vertentes de pesquisa histórica, ela vai contribuir para uma certa compreensão de pesquisa e de revisão.
NO: Em seus estudos, há a afirmação de que a telenovela, enquanto ficção, participa ativamente na construção da realidade. Como interpretar a extensão dessa afirmação?

MLM: Eu disse há pouco que existe uma relação muito forte entre indústria cultural e o que a telenovela está propondo. Neste jogo existe essa realimentação das nossas dimensões de realidade. Todas as questões que estão na ficção, são modelos de comportamento, são idéias, e elas não vão ficar desvinculadas das nossas práticas. Muitas vezes elas vão acabar guiando as nossas práticas e as nossas decisões. A interferência que a ficção tem é muito forte. A ficção não seria alguma coisa desvinculada da realidade, pelo contrário, ela está plantada na realidade. Quer dizer, as liberdades que ela tem, a reorganização que ela faz, é uma questão de codificação, mas não uma questão de qualidade muito diferente no que diz respeito à realidade mesmo como fonte. Não adianta autores dizerem que a telenovela dele não tem vinculação nenhuma com a realidade, que ele vai estar brincando com fantasmas, com castelos, com assombrações, com vampiros, sei lá o quê! Mas por mais que ele queira dar asas a essa fantasia e trazer esses monstrinhos e esses seres, ainda assim, ele terá que ter uma estrutura realista para colocar esses monstrinhos porque senão acabará em um "non sense". Há uma frase que eu acho fantástica, do paraguaio Augusto Roa Bastos, historiador, que não se considera como tal e diz fazer ficção antes que os historiadores acabem com a história do seu país, evidenciando seu viés contestador. É um pouco isso, você tem a questão das interferências ideológicas, a questão da versão oficial, modos de fazer historia e modos de fazer fiç̧ão. Agora a ficção pode se aproximar muito mais daquilo que seria um momento de realidade do que o próprio discurso desprovido, baseado unicamente no factual, extremamente racional, objetivo, enfim, baseado em elementos objetivos. 
Então eu acredito que a ficção é a grande saída, primeiro porque é uma forma de suportar a realidade dura. Por outro lado, me encanta ver como os autores de telenovela tramam as coisas, como é que eles armam coisas que conseguem nos surpreender. Claro que estamos falando de telenovela, mas poderíamos citar a literatura, quando um autor, como Paul Auster, em A Noite do Oráculo, nos faz cair em armadilha. Acompanhamos a história que ele está escrevendo como roteiro para um filme, interrompida num ponto de grande expectativa e quase sem possibilidade de solução. Já devoramos páginas e mais páginas esperando a retomada da história e nos aproximamos do final quando o roteirista desiste do projeto. Sem conseguir terminar, os originais são rasgados e atirados no lixo. O autor consegue nos enredar com o desafio de nossa curiosidade para o "como é que isso vai terminar" e nossa impossibilidade criativa de formular uma saída para o impasse A idéia me parece fantástica por burlar nossa atenção e nos surpreender num comportamento de leitor de primeiro nível (Umberto Eco), afinal o protagonista está fazendo o seu trabalho de produzir roteiros e ele pode jogar fora a história que não consegue terminar.

NO: Comente um pouco esse caráter da telenovela brasileira ter o status de um produto genuinamente brasileiro, sobretudo no contexto internacional?

MLM: É um conjunto de fatores que foram se associando no curso do tempo, da própria constituição da televisão brasileira, e da seriedade e do realismo com que se encara a ficção, eu acho que ai está a contradição, é visto como uma coisa muito séria, e na medida que é vista como uma coisa muito séria, ela é feita com muito esmero, com muito cuidado. Então eu acho que o que faz a telenovela brasileira ter esta cara genuinamente brasileira é ela ter seguido um rumo de respeito ao público enquanto oferecimento de ficção, e por outro lado trazer este próprio público para dentro da telenovela na medida em que se traz o cotidiano do país, dos diversos segmentos sociais, enfim, dos problemas que a gente vive. Nessa troca, está o genuinamente brasileiro porque a sintonia com a realidade, com a vida cotidiana, com as necessidades, com as aflições, enfim, ela é permanente.

NO: O êxito internacional da telenovela brasileira, em mais de 100 países do mundo, deve-se à dimensão mercadológica que a sustenta ou à peculiaridade da cultura brasileira sendo aceita?

MLM: Acredito no saber fazer como um eixo definitivo. Essa sintonia com as temáticas do momento, dado que não vivemos isolados, estamos em um mundo globalizado e as coisas não ficam restritas a fronteiras, essa sintonia com o presente, mesmo quando se trata do passado, este zelo, e esta capacidade de saber fazer. A ênfase na narrativa, na história bem contada é muito importante, na medida em que o contar e o ouvir histórias é elemento essencial na vida do homem. Mesmo quando ela está refletindo uma cultura particular ou está tratando de temas que não nos diz respeito diretamente, nós acabamos nos envolvendo. É uma maneira de identificarmos a humanidade comum em meio ao diverso. Da mesma maneira que há interesse por aquilo que vem de outros, seja uma telenovela portuguesa, também eles se encantam com as histórias bem contadas que produzimos, que mostram um pouco da nossa cultura, do nosso modo de ser e agir. Por um outro lado existe uma série de elementos que são absolutamente comuns, são os dramas humanos que vão estar se repetindo. Nesse sentido a historia não teria fronteiras. E uma historia bem acabada, bem escrita, com todos os cuidados, acaba tendo uma certa prioridade atravessando fronteiras, da mesma forma que os filmes de Hollywood. O contar histórias, a narrativa é realmente fundamental. E aí as fronteiras, sejam econômicas, sejam 
culturais, acabam ficando mais diluídas.

NO: Comente as críticas insistentes recebidas pela telenovela de que ela promove uma massificação de valores em quem a consome.

MLM: Não acredito na massificação de valores. Primeiro que a ficção é bem entendida como ficção, segundo que nós já temos um público extremamente critico com relação à própria ficção e a produção. Por outro lado eu acho que as pessoas dialogam, contestam, gostam não gostam, discutem com a telenovela, mas elas não vão ser doutrinadas, nem domesticadas. Existe uma compreensão da ficção em que ela é percebida, e não se trata propriamente de domesticar, mas de mostrar determinadas questões, tirar determinada inocência, sobretudo no campo da política, mas daí o que é que a gente colocaria, é uma pergunta que eu também me faço, a pensar por este lado, o que a gente colocaria no lugar se tirasse essa ficção, por que se ela virasse uma coisa erudita, panfletagem ou coisa do gênero, ela também estaria descaracterizada. O que se colocaria no lugar? Será que nós daríamos leituras para o povo brasileiro? Nós colocaríamos todos os itens de todas as bibliotecas à disposição, enfim, passa pelo problema da educação. Questiona-se se a ficção consumida é compreendida com tal. $\mathrm{Eu}$ acho que não existem equívocos, as pessoas não misturam as coisas, não são convencidas pela ficção, pelo contrario, elas vão ver determinados conflitos, determinadas situações sendo postas ali. Quer dizer, os conflitos que elas vivem aqui de repente estão lá. Mas existe uma maneira de resolver lá, a imaginação não é cerceada pelo fato de não ser altamente estimulada ou ser provocada. Então que imaginação seria essa? Pelo contrário, a própria telenovela estimula a imaginação na medida em que ela propõe determinados modelos e constituem desafios. E mais, para alguns ela tem uma função meramente lúdica de observar determinados hábitos, determinados costumes. A telenovela alcança agora o que não se alcançou com outras tentativas, seu potencial é muito grande. Mas vai depender naturalmente das cabeças dos roteiristas e do interesse na preservação dessa independência na produção, no sentido de que não é uma coisa que está "a serviço de". Por outro lado, está claro que existem oportunismos, e o veio do merchandising social, da responsabilidade social, passa a ser uma bandeira quando se integra à ficção com a intenção de promover algo de caráter social. Eu acredito que existe uma ampliação progressiva da exigência com relação a tais compromissos e o entretenimento abre espaço para abrigar elementos educativos e formativos da cidadania. 